\title{
On the benchmarking of friction in timing chains
}

\author{
Lenard Jurj $^{1}$ and Radu Velicu, ${ }^{1, *}$ \\ ${ }^{1}$ Transilvania University of Brasov, Product Design Mechatronics and Environment Department, Eroilor 29, 500069 Brasov, Romania
}

\begin{abstract}
This paper is dealing with the evaluation of friction in timing chains. Benchmarking friction is based on the experimentally determined friction losses in basic chain drives with transmission ratio $i=1$. This friction is not including friction losses in bearings. These results should be used, in the simplest manner, in order to evaluate friction in timing chains $(i=2)$. We are presenting the theoretical approach and experimental validation that have been developed for the timing chain drives, with transmission ratio $i=2$. Friction losses are presented as resistant friction torques at the input shaft, depending on input rotational speed and tensioning force in the chain drive.
\end{abstract}

\section{Introduction}

This scientific research is developed in the frame of the 20/20/20 goals stipulated by the Directive for Energy Eficiency of the European Union (2012/27/UE). This imposes the goals of automotive industry for year 2020. Targets in the equivalent $\mathrm{CO} 2$ emissions and fuel economy have been set. American standards CAFE (Corporate Average Fuel Economy) are imposing a one third reduction of fuel consumption, compared to year 2008. European Commission set a goal for 2021 of average CO2 emissions of 95 grams CO2 / km for the whole fleet produced in 2020. This means an average fuel consumption of 4.11 petrol/100 km or $3.61 \mathrm{Diesel} / 100$ $\mathrm{km}$.

Benchmarking friction in timing chains is only a little step in the direction of reducing the losses in the timing system of the combustion engine. According to [1-4] 30$35 \%$ of the fuel energy consumed in automobiles are needed to overcome friction in the combustion engine systems.
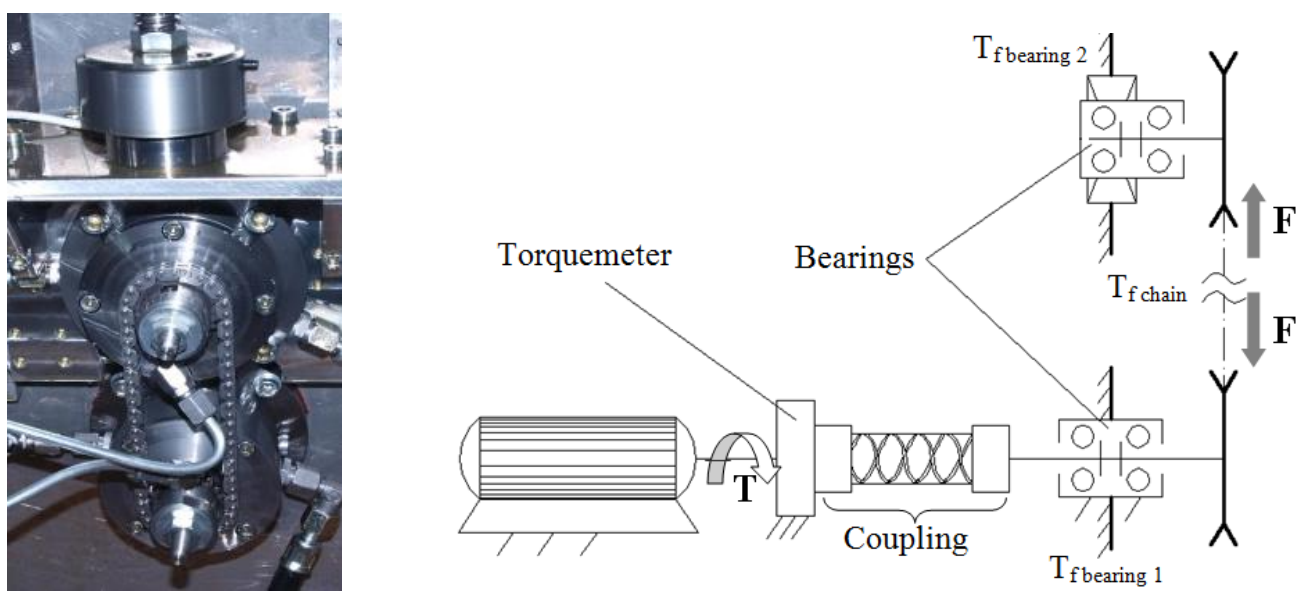

Fig. 1. Image and functional diagram of the chain friction rig

\footnotetext{
* Corresponding author: rvelicu@unitbv.ro
}

(C) The Authors, published by EDP Sciences. This is an open access article distributed under the terms of the Creative Commons Attribution License 4.0 (http://creativecommons.org/licenses/by/4.0/). 
In the format presented in Figure 1, the rig measures the input torque $T$ (global friction torque), for a basic chain drive with $i=1$, identical chain sprockets with number of teeth $z_{1}=z_{2}=23$, chain with 64 links, different rotation speed $n$ in the range $500 \ldots 5000 \mathrm{rot} / \mathrm{min}$, different tensioning of the chain drive $F$ and different temperature of the 5W30 oil for chain lubrication.

$$
T=T_{\text {chain+bearings }}=T_{f \text { chain }}+T_{\text {fbearing } 1}+T_{\text {fbearing } 2}
$$

The rig can be adapted in the format presented in [7], in order to measure separately the friction in the two bearings, results presented in $[8,9]$

$$
T=T_{\text {bearings }}=T_{\text {fbearing } 1}+T_{\text {fbearing } 2 .}
$$

Friction in chain results from extracting the measured friction torque in bearings from the measured global friction torque

$$
T_{\text {fchain }}=T_{\text {chain }+ \text { bearings }}-T_{\text {bearings }}
$$

More details on the testing procedure are presented in [7].

\section{Theoretical approach on chain friction}

In the theoretical approaches of chain friction, the literature is generally considering only the friction in the cylindrical joints between links. The other possible friction between links and sprockets is considered negligible. The approaches presented in [10, 11] are calculating mechanical efficiency or power loss by friction, but not the resulted friction torque.

For the following theoretical approach, we consider a a chain transmission with two sprockets, tensioning with variable centre distance, transmission ratio $i$. Figure 2 presents the calculus diagram with a detail of a cylindrical joint with friction. A silent chain is presented but the results are valid also for bush and roller chains.

Friction losses appear in points 1' and 1" (entering and exiting the driving sprocket 1 ) and also in points 2 ' and 2" (entering and exiting the driven sprocket 2 ).

The friction forces in joints 1', 1', 2' and 2", $F_{f y}$, result as:

$$
F_{f y}=\mu \cdot F_{y},
$$

where: $\mu$ is the friction coeficient between bolt and link, $F_{y}$ is the force along the chain $\left(F_{1}-\right.$ for points 1 " and 2", $F_{2}$ - for points 1' and 2',

In all these points there is a relative rotation of the link on the bolt. If $\theta=360^{\circ} / z_{1}$ is the angular pitch of the driving sprocket 1 , for a rotation with angle $\theta$ of the driving sprocket 1 , in each point 1 ' and 1" we will have a relative rotation with angle $\theta$ of the link on the bolt. In each point 2 ' and 2" we will have a relative rotation with angle $\theta / i$ $\left(360^{\circ} / z_{2}-\right.$ angular pitch of sprocket 2$)$ of the link on the bolt.

For a rotation with angle $\theta$ of the driving sprocket 1 , the mechanical work $L_{f y}$ of the friction forces, in joints 1', 1 ", 2' and 2" results as:

$$
\begin{aligned}
& L_{f 1^{\prime}}=F_{f 1^{\prime}} \cdot \frac{d_{b}}{2} \cdot \theta=\mu \cdot F_{2} \frac{d_{b}}{2} \cdot \theta, \text { for joint } 1 \\
& L_{f 1^{\prime \prime}}=F_{f 1^{\prime \prime}} \cdot \frac{d_{b}}{2} \cdot \theta=\mu \cdot F_{1} \frac{d_{b}}{2} \cdot \theta, \text { for joint } 1 " \\
& L_{f 2^{\prime}}=F_{f 2^{\prime}} \cdot \frac{d_{b}}{2} \cdot \frac{\theta}{i}=\mu \cdot F_{2} \frac{d_{b}}{2} \cdot \frac{\theta}{i}, \text { for joint } 2 \\
& L_{f 2^{\prime \prime}}=F_{f 2^{\prime \prime}} \cdot \frac{d_{b}}{2} \cdot \frac{\theta}{i}=\mu \cdot F_{1} \frac{d_{b}}{2} \cdot \frac{\theta}{i}, \text { for joint } 2 ”
\end{aligned}
$$

where $d_{b}$ is the diameter of the bolt.
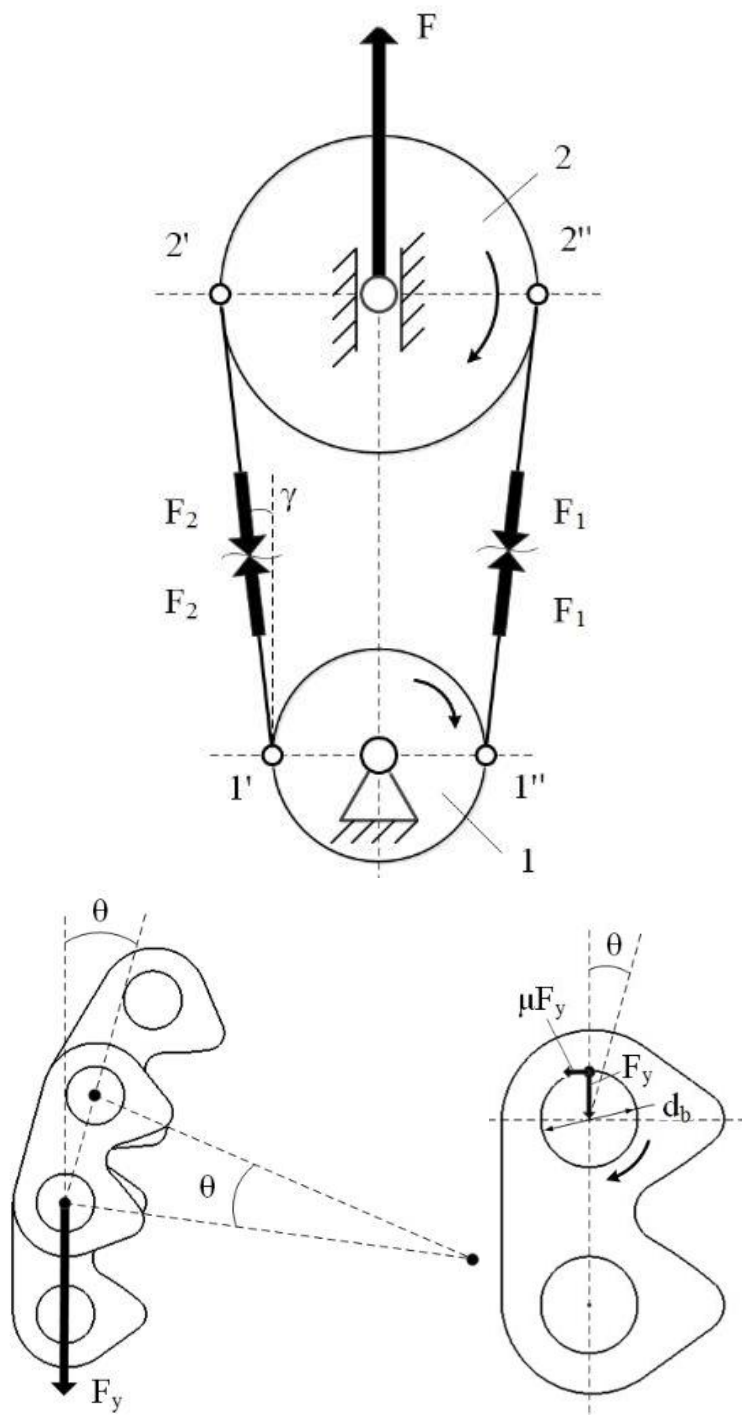

Fig. 2. Diagram of friction losses in chain drives

The friction torque reduced at the driving sprocket 1 results by equalizing the sum of mechanical works of friction forces with the mechanical work of the friction torque at the driving sprocket $T_{f} \theta$ :

$$
\begin{aligned}
T_{f} & =\frac{\sum L_{f y}}{\theta}=\frac{\mu\left(F_{1}+F_{2}\right) \frac{d_{b}}{2} \cdot \theta\left(1+\frac{1}{i}\right)}{\theta}= \\
& =\mu\left(F_{1}+F_{2}\right) \frac{d_{b}}{2}\left(1+\frac{1}{i}\right)
\end{aligned}
$$

Depending on the tensioning force, which can be aproximated as $F=\left(F_{1}+F_{2}\right) \cos \gamma$, the friction torque is: 


$$
T_{f}=\mu F \frac{d_{b}}{2}\left(1+\frac{1}{i}\right) \cos \gamma .
$$

For $i=1, \gamma=0$

$$
T_{f(i=1)}=\mu F d_{b}
$$

For $i=2$,

$$
T_{f(i=2)}=0.75 \mu F d_{b} \cos \gamma=0.75 T_{f(i=1)} \cos \gamma .
$$

The power loss by friction is

$$
P_{f}=T_{f} \omega=\mu F \omega \frac{d_{b}}{2}\left(1+\frac{1}{i}\right) \cos \gamma .
$$

where $\omega$ is the angular speed of the driving sprocket.

As it can be noticed from equations (9) and (12), from the theoretical point of view, the friction torque and the power loss doesn't depend on number of teeth or chain pitch, but they are directly depending on friction coefficient, bolt diameter and initial tensioning.

\section{Experimental results. Validation}

Figure 3 presents the diagrams determining chain friction $T_{f}$ chain by extracting the measured friction torque in bearings $T_{\text {bearings }}$ from the measured global friction torque $T_{\text {chain+bearings }}$ (see eq. (3)). The values of all the torques are presented as percentage of the value of $T_{\text {fchain }}$ resulted for $n=500 \mathrm{rot} / \mathrm{min}$ and $\mathrm{F}=1 \mathrm{kN}$.

$$
T_{\%}=T / T_{\text {fchain }(n=500 \mathrm{rot} / \mathrm{min}, \quad F=1 \mathrm{kN})} 100 .
$$

For a good comparison, the diagrams from Figure 3 have the same scale. The results presented in Figure 3 are from the testing of a basic silent chain drive $(i=1)$ with a pitch of $6.35 \mathrm{~mm}$ [12], at a temperature of chain oil of 90 ${ }^{\circ} \mathrm{C}$ and a temperature of bearings oil of $50{ }^{\circ} \mathrm{C}$, for two values of tensioning. The results show that:

- Friction torque in chain is depending mostly on the tensioning, while speed influence is irrelevant; This is partially validating the theory (see eq. (10));

- Friction in bearings has a very small influence from tensioning but an important influence from rotational speed.

For testing friction in the chain drive with $\mathrm{i}=2$ (like the case of timing chains) we used the same chains tested at $i=1$ (23-23 teeth sprockets, 64 links), replacing one of the sprockets with a 46 teeth sprocket (see Figure 4).

Due to the fact that the upper bearings are working at half the speed of the diving shaft (lower bearings), we needed to measure the bearings friction also for input rotational speeds at half the values from initial testing, in the range $250 \ldots 2500 \mathrm{rot} / \mathrm{min}$. Because we only measure the sum of bearing friction of the two bearings at the same rotational speed $T_{\text {bearings }}(n)$, we calculated the bearings friction from situation with $i=2$ as

$$
\begin{gathered}
T_{\text {bearings }(i=2)}(n)=T_{\text {fbearing } 1}(n)+\frac{1}{i} T_{\text {fbearing } 2}(n / 2)= \\
\quad \frac{1}{2} T_{\text {bearings }(i=1)}(n)+\frac{1}{4} T_{\text {fbearings }(i=1)}(n / 2) .
\end{gathered}
$$
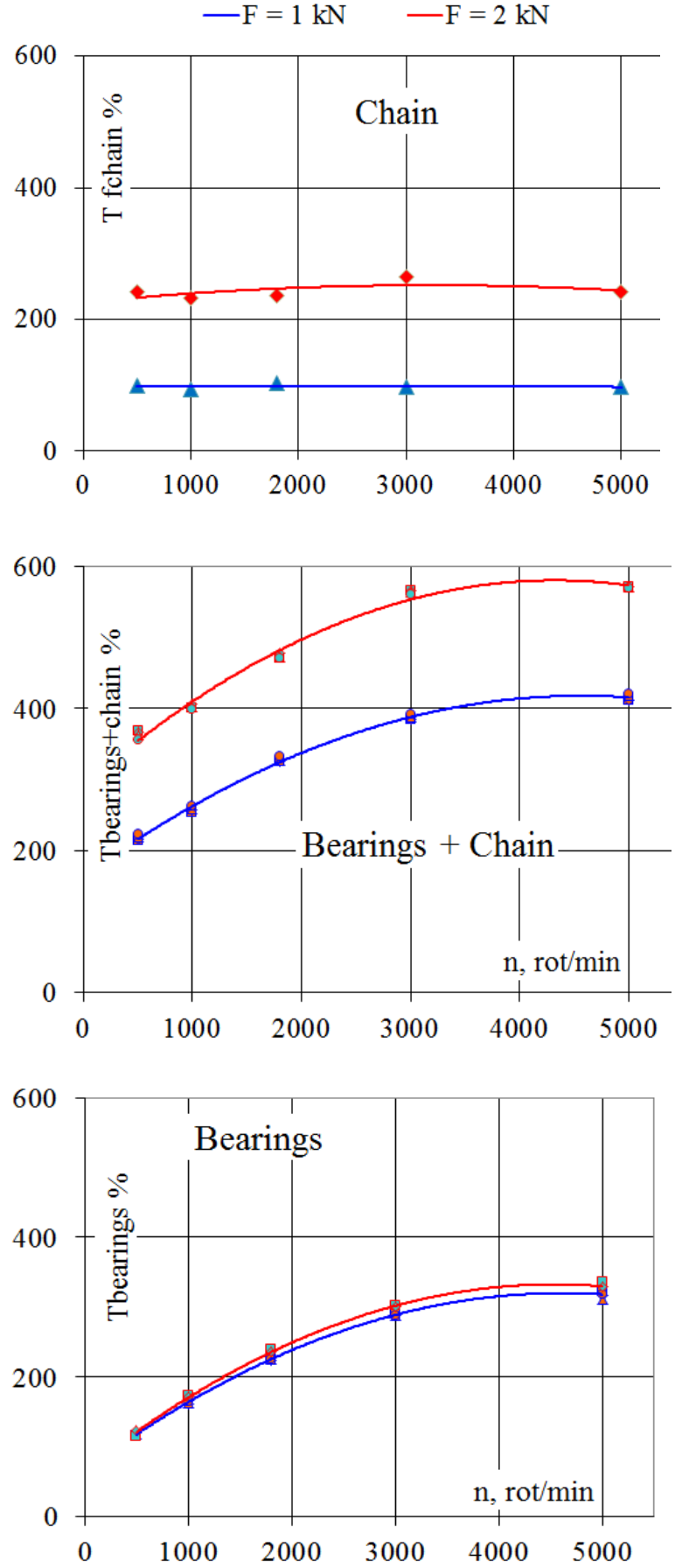

Fig. 3. Chain friction determined by subtracting bearings from global friction

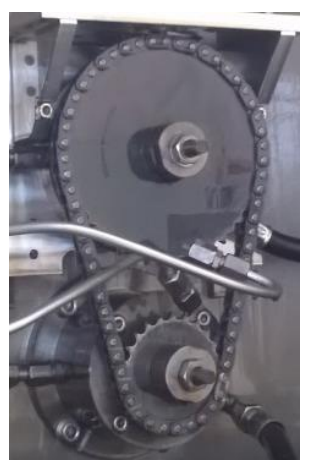

Fig. 4. Testing chain drive with $i=2$ 
Equation (14) is based on the following assumptions: - Friction in the two bearings are equal;

- $T_{\text {bearings ( } i=2)}$ is calculated as torque at the input (driving) shaft so the friction torque at upper bearing $T_{\text {bearing } 2}$ must be reduced at the input shaft by multiplying with $1 / i$.

Chain friction for $i=2$ situation is calculated by subtracting the bearings friction $T_{\text {bearings (i=2) }}$ (eq. (14)) from the measured global friction $T_{\text {chain+bearings (i=2) }}$ Figure 5 presents the resulted friction torques measured for $\mathrm{i}=2$, for two type of chains [12] (a - bush chain with $7 \mathrm{~mm}$ pitch, 7B and $\mathrm{b}$ - silent chain with $6.35 \mathrm{~mm}$ pitch, $6 \mathrm{~S}$ ). Measurements have been made at a temperature of chain oil of $90^{\circ} \mathrm{C}$ and a temperature of bearings oil of $50{ }^{\circ} \mathrm{C}$, for two values of tensioning.

There are also presented, for comparison, the chain friction resulted for $i=1$ situation and the theoretical calculus of $T_{f(i=2)}$ depending on measured $T_{f(i=1)}$ (see eq. (11)). For our calculus $\cos \gamma=0.9781$. For each diagram, the values of all the torques are presented as percentage of the value of $T_{\text {f chain } i=2}$ measured for $\mathrm{n}=500 \mathrm{rot} / \mathrm{min}$ and $\mathrm{F}$ $=1 \mathrm{kN}$.
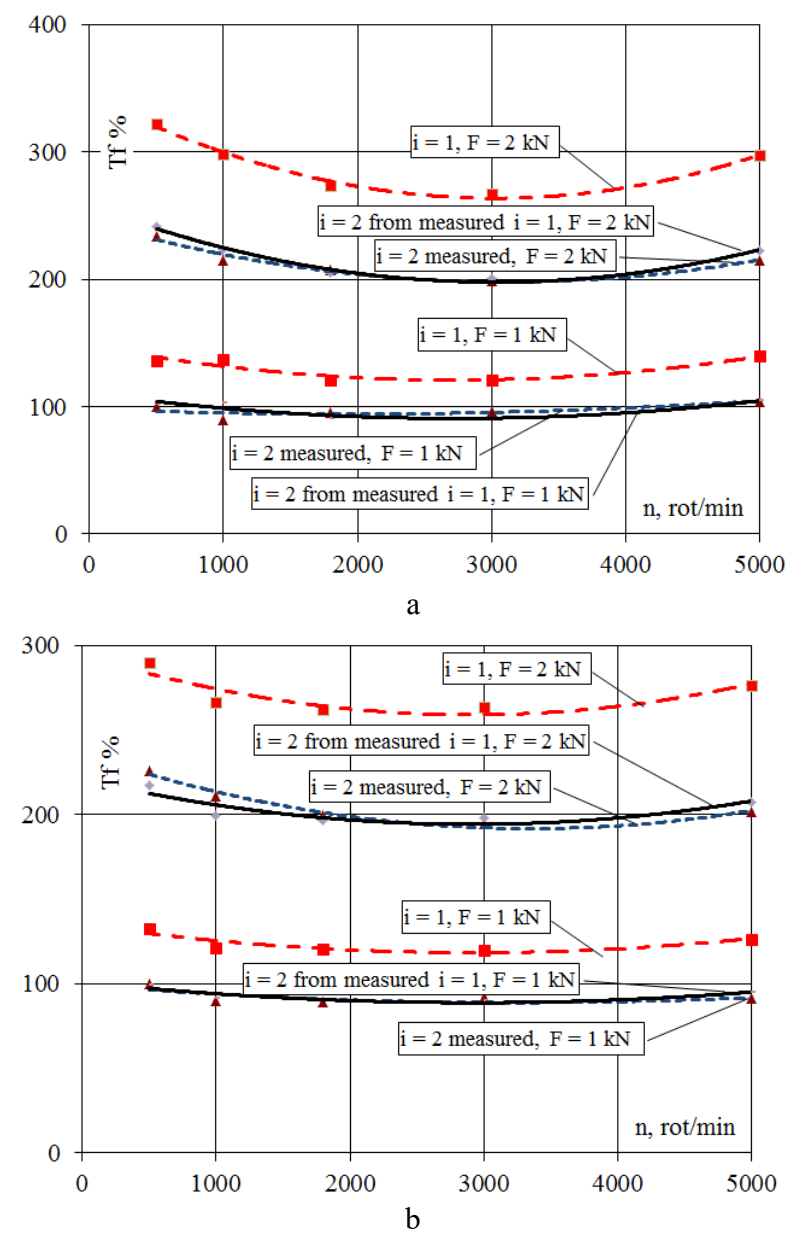

Fig. 5. Chain friction for $i=2$

The comparison between the measured $i=2$ situation and the resulted from $i=1$ measurements shows very close values for all the range of rotational speed and tensioning. This is validating the calculated chain friction $T_{f(i=2)}$ depending on measured $T_{f(i=1)}$ (see eq. (11)).

\section{Conclusion}

A very simple equation is linking the friction measured on a basic transmission with the case of the timing chain $(i=$ 2 ). The next research for benchmarking friction in chain drives should focus on the following directions:

- guide friction contribution to the global friction of the chain drive;

- optimizing the initial tensioning, this being the main parameter influencing chain friction.

\section{References}

1. S.C. Tung, M.L. McMillan, Tribol. Int. 37 (7), 517 (2004)

2. K. Holmberg, P. Andersson, A. Erdemir, Tribol. Int. 47 (14), 221 (2012)

3. M. Schwaderlapp, F. Koch, J. Dohmen, Seoul 2000 FISITA World Automotive Congress, 1 (2000)

4. C.M. Taylor, Wear 221, 1 (1998)

5. T. Hyakutake, M. Inagaki, M. Matsuda, N. Hakamada, Y. Teramachi, JSAE Review 22, 5 (2001)

6. A. Todi-Eftimie, R. Velicu, R. Saulescu, C. Jaliu, Adv. Mat. Res. 753-755, 1110 (2013)

7. R. Velicu, M. Lates, Annals of the Oradea University, Fascicle of Management and Technological Engineering XIV (XXIV), 59 (2015)

8. R. Velicu, S. Popa, Annals of the Oradea University, Fascicle of Management and Technological Engineering XV (XXV), 5 (2016)

9. M. Lates, R. Velicu, R. Papuc, (2014) International J. Surf. Sc. and Eng., 8 (4), 345 (2014)

10. B. Horovitz, Transmissions and variable transmissions with chains and belts (in Romanian) (Ed. Tehnica, Bucuresti, 1971)

11. G. Niemann, Machinenelemente. Band. II. (Springer Verlag, Berlin, 1975)

12. Schaeffler Group Automotive Schaeffler Chain Drive Systems Catalogue (2009) 